\title{
Vulvar Squamous Intraepithelial Lesion
}

National Cancer Institute

\section{Source}

National Cancer Institute. Vulvar Squamous Intraepithelial Lesion. NCI Thesaurus. Code C128142.

An intraepithelial lesion of the vulvar squamous epithelium commonly associated with HPV infection. It includes low and high grade squamous intraepithelial lesions. Low grade squamous intraepithelial lesion is considered a non-neoplastic lesion. High grade squamous intraepithelial lesion is neoplastic. 